\title{
El fons còsmic de microones i l'origen de l'Univers
}

Eduard Massó, Departament de Física, Àrea de Física Teòrica, Universitat Autònoma de Barcelona Joan Aliberas, IES Josep Puig i Cadafalch, Mataró

Datat 13.700 milions d'anys enrere, l'origen de l'Univers pot semblar difícil d'investigar després d'haver passat tant de temps. Però el treball de Mather i Smoot sobre el fons còsmic de radiació de microones - gràcies al qual han guanyat el premi Nobel de física del 2006- ha proporcionat noves evidències sobre el que va passar en èpoques tan remotes.

El treball de Mather i Smoot ha proporcionat importants dades sobre l'Univers, fins llavors desconegudes. Són importants perquè la seva anàlisi aporta tant un salt de progrés en el coneixement científic com una altra lliçó d'humilitat, de manera semblant al que ja havia passat en altres avenços històrics.

Lliçons d'humilitat i salts endavant com els que van significar l'abandó d'algunes concepcions aparentment ben establertes: que la Terra és el centre de l'Univers, que ho és el Sol, que la Galàxia és tot l'Univers...

Ara les noves dades ens condueixen a la convicció que la matèria que palpem, la formada per àtoms, és una part molt minoritària del contingut de l'Univers.

Queda molt més per descobrir del que ens imaginàvem.

Però comencem pel principi.

\section{UN SOROLL MOLEST}

Els primers satèl-lits de telecomunicació, anomenats Eco, consistien en grans globus plens de gas i servien per reflectir passivament ones de ràdio i així permetre la comunicació entre punts allunyats. Com que els senyals que arribarien eren molt dèbils, es van haver de crear grans antenes per poder-les captar.

Una d'elles la construí la companyia telefònica Bell Laboratories a Nova Jersey (EUA) el 1960. Dos joves empleats, radioastrònoms de formació, Arno Penzias i Robert Wilson (fig. 1), maldaven per utilitzar-la com a radiotelescopi. Finalment el 1962, amb la posada en òrbita del Telstar, el primer satèl-lit actiu de telecomunicacions, l'antena quedà alliberada de la seva funció original i ells la pogueren utilitzar.

Aviat van topar amb un senyal que els apareixia en totes les observacions. Per a ells era un molest soroll. Comprovaren que no canviava amb la direcció que posaven l'antena ni amb l'època de l'any. Van sospitar de l'aparell, dels entorns, dels coloms, de factors remots...

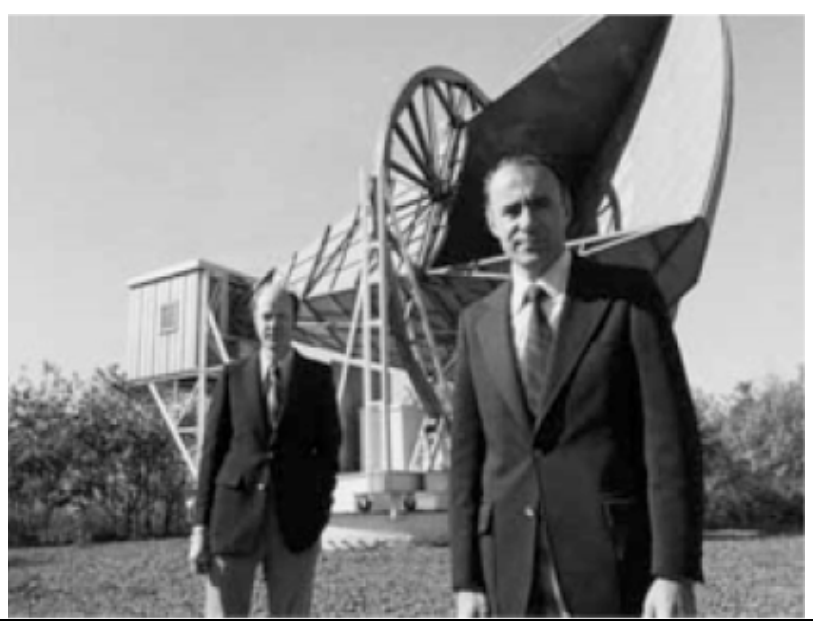

Figura 1. Penzias i Wilson, premis Nobel de física el 1978, amb l'antena de Holmdel, Nova Jersey, anys després que els ajudés a descobrir el fons còsmic de microones.

El 1929 l'astrònom nord-americà Edwin Hubble havia publicat el seu treball cabdal on demostrava que les galàxies s'allunyen de nosaltres amb una velocitat proporcional a la distància.

Això havia donat peu a pensar que tota la matèria havia sortit d'un sol punt, elaborant la teoria que s'anomenà, irònicament, del Big Bang o Gran Explosió. Una explosió que s'hauria produït uns 13.700 milions d'anys enrere: un escenari tan re- 
mot que difícilment ningú podia pensar sèriament en obtenir-ne dades... suposant que la teoria tingués algun sentit.

Penzias i Wilson, experts en microones (les ones electromagnètiques amb longituds d'ona entre $10^{-5}$ i $\left.10^{-1} \mathrm{~m}\right)$, van publicar les seves dades el 1965, sense buscar-hi interpretació.

\section{UN COS NEGRE ANOMENAT UNIVERS}

És prou conegut que el 1900 l'alemany Max Planck havia aconseguir explicar, mitjançant la hipòtesi de la quantització de la radiació, l'espectre de radiació d'un cos negre. Segons la seva temperatura, la distribució de les freqüències que emet un cos negre és diferent (fig. 2).

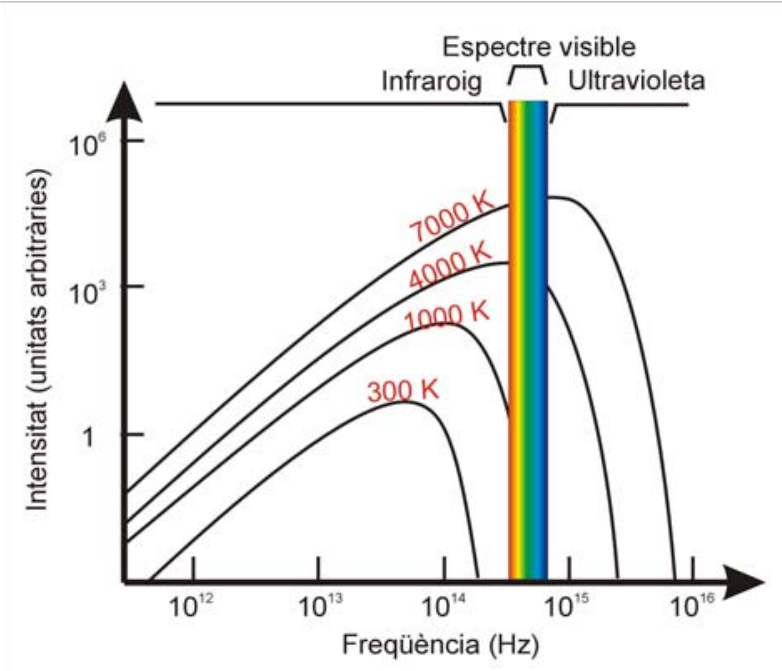

Figura 2. Intensitat de la radiació emesa per un cos negre en funció de la freqüència per a algunes temperatures.
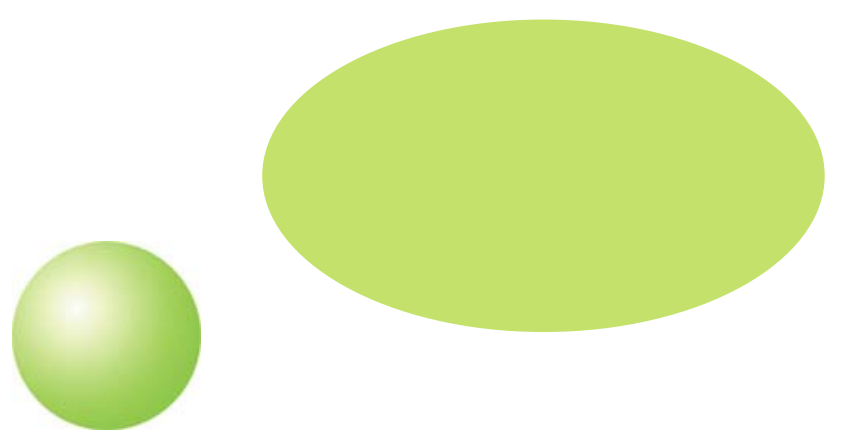

Figura 3. Planisferi celest mostrant l'isotropia del fons còsmic de microones en una escala de 0 a 4 K. El planisferi representa la seva distribució homogènia a l'esfera celest (imatge petita).
Però la radiació descoberta per Penzias i Wilson corresponia a la d'un cos negre a una temperatura de 2,728 K. Coincidia amb la que, segons els càlculs, tindria actualment la radiació produïda en el Big Bang, un cop "refredada" per l'expansió de l'Univers des de llavors. Avui dia es coneix com a fons còsmic de microones.

Podríem representar aquesta radiació per a cadascuna de les direccions de l'espai mitjançant un planisferi, indicant en fals color la temperatura: del blau $(0 \mathrm{~K})$ al roig $(4 \mathrm{~K})$. Però com que és idèntica en totes les direccions, isòtropa, la imatge no tindria detalls (fig. 3).

Però el 1989 la NASA posava en òrbita un satèl-lit, COBE (fig. 4), per mesurar amb més precisió la radiació còsmica de fons.

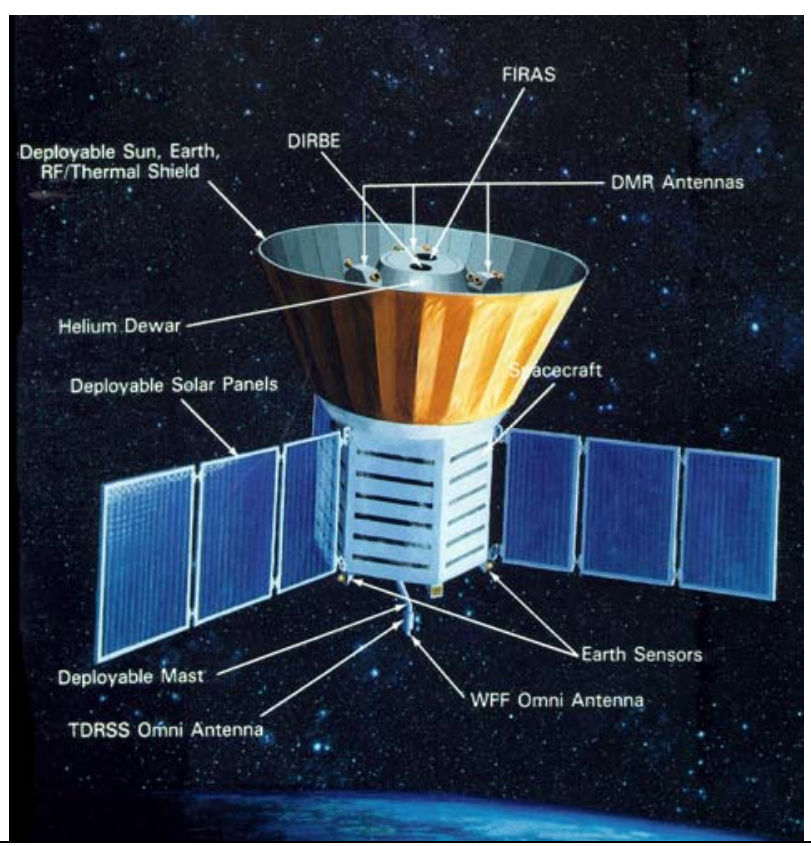

Figura 4. El satèllit COBE i els seus principals components. Estava dissenyat per tenir els panels solars sempre encarats a la llum del Sol, mentre que els instruments en quedaven protegits per un escut tèrmic i una orientació convenient. Al mateix temps, les antenes de comunicació apuntaven sempre a la Terra. (NASA)

Els que afirmen que la ciència està allunyada de les emocions no saben el que diuen. No saben què se sent al contemplar la gràfica obtinguda per John Mather i George Smoot (fig. 5), mitjançant els instruments de la nau i publicada el 1990. Perquè és impressionant la gesta que suposa la construcció dels instruments, la brevetat de la observació (només 9 minuts per obtenir aquestes dades) i la bellesa de la corba (l'espectre de cos negre més perfecte que mai s'ha obtingut).

També cal destacar que els intervals d'error en la mesura de la intensitat, que apareixen en la gràfica com a petites barres per a cada mesura, han 
estat multiplicats per 100 per poder resultar visualment apreciables. Són mesures increïblement precises!

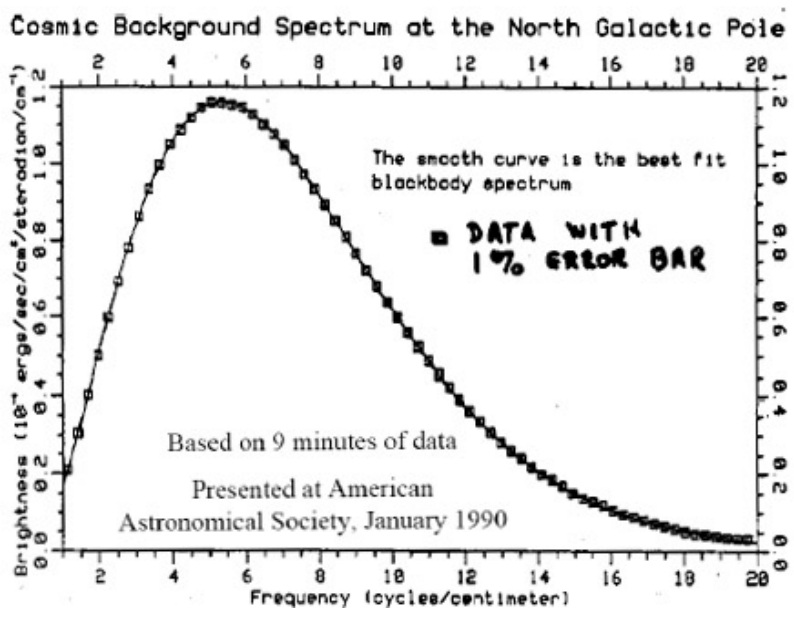

Figura 5. Espectre del fons còsmic en el Pol Nord galàctic, obtingut mitjançant el satèl-lit COBE. (NASA)

La pregunta que el lector es pot fer a continuació és previsible: si els espectres de radiació observats arreu presenten fluctuacions importants, què significa que la radiació còsmica de fons respongui tan bé a la corba teòrica?

Les fluctuacions esmentades són degudes a desequilibris de temperatura més o menys importants, que es donen en la majoria de sistemes. Que la radiació de l'Univers no les mostri és una impressionant evidència que, quan es van emetre, tot ell era en equilibri tèrmic. I això només és possible per una forta interacció entre totes les seves parts.

Això sol ja descarta uns quants models d'evolució de l'Univers i n'afavoreix uns altres. Encara que no semblava possible, estem obtenint informació molt directa del que va passar en les primeres etapes en l'evolució de l'univers!

\section{UNA RADIACIÓ UNIFORME... QUE NO HO ÉS DEL TOT}

El tractament de les imatges el podem resumir de la següent manera.

Les mesures obtingudes en totes direccions estan recollides en la imatge de la fig. 6 i mostren grans diferències entre diferents direccions.

Però com que són degudes a fenòmens més o menys ben coneguts, es podran anar retirant de les dades restant els valors corresponents fins a deixar únicament les radiacions del fons còsmic de microones.
Un d'aquests fenòmens és la llum zodiacal, originada en el nostre Sistema Solar i que aquí travessa tot el planisferi en forma d'una gran S.

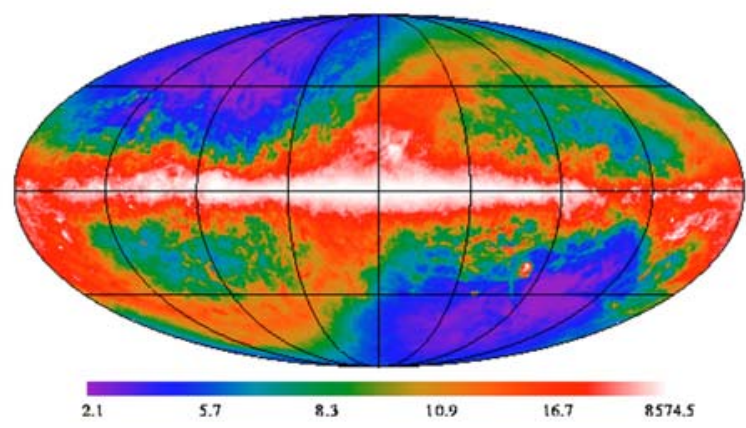

Figura 6. Representació, en coordenades galàctiques, de les dades en brut obtingudes mitjançant COBE. La franja blanca, propera al seu pla equatorial, correspon a la part més densa de la Via Làctia. (NASA)

Un altre fenomen eliminable és l'efecte Doppler causat pel moviment del Sistema Solar respecte d'astres llunyans. Això provoca que en la direcció del cel cap a on ens dirigim les radiacions es desplacin cap al blau, mentre que les oposades ho fan cap al roig (fig.7). Aquestes desviacions corresponen a diferències de temperatura de tan sols $\pm 3,353 \mathrm{mK}$, aproximadament una part de cada mil.

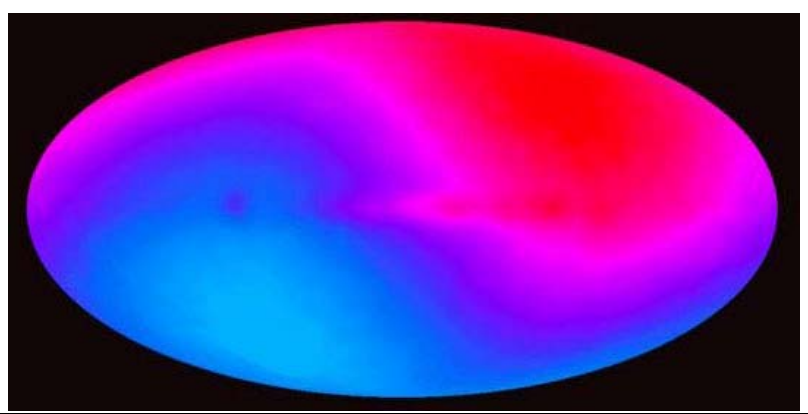

Figura 7. Efecte del desplaçament de la Terra alterant les longituds d'ona de la radiació còsmica de fons. (NASA)

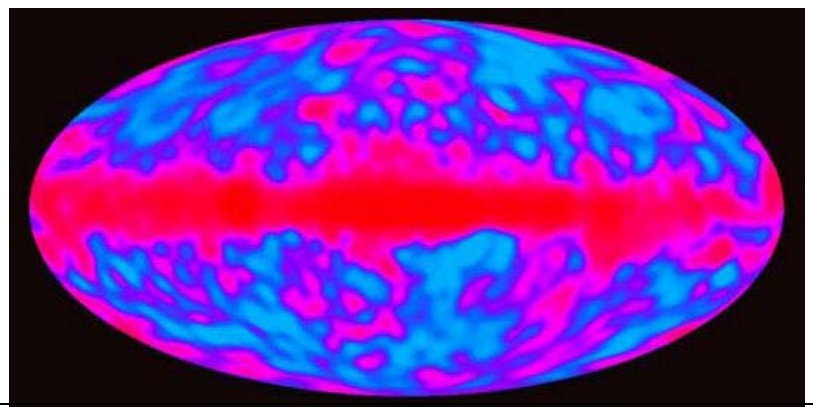

Figura 8. Distribució de radiació de fons juntament amb la de la galàxia, que apareix principalment a la part equatorial. (NASA) 
Una vegada eliminat aquest efecte (fig. 8) cal restar també la radiació provinent de la galàxia, degudament modelitzada.

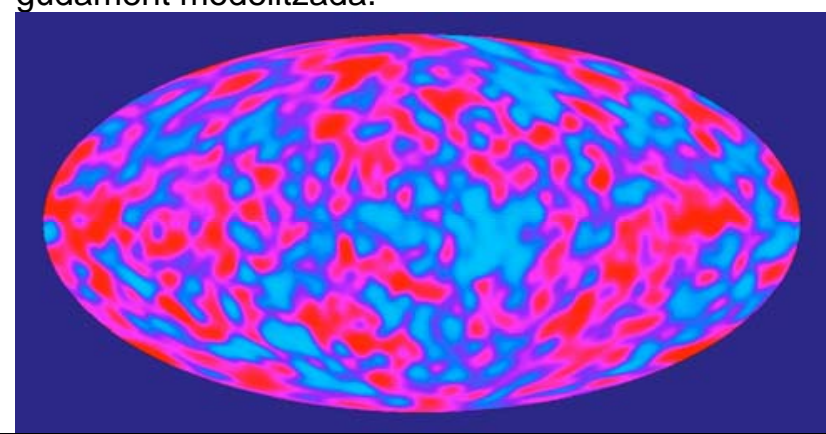

Figura 9. Imatge final de les diferències en la radiació còsmica de fons. Corresponen a diferències de temperatura de $\pm 18 \mu \mathrm{K}$ (aproximadament $10^{-5}$ K). Els resultats es publicaren el 1992. (NASA)

Després d'aquestes i altres supressions s'obté la distribució de la radiació còsmica de fons. L'admirable resultat final es pot apreciar a la coneguda imatge de la fig. 9.

Paradoxalment, doncs, a més de comprovar la gran uniformitat de la radiació còsmica de fons, l'altre gran èxit de COBE va ser permetre constatar que aquesta radiació no era del tot uniforme.

Ambdós descobriments de Matter i Smoot són els que va premiar el jurat atorgant-los recentment el Nobel de física (fig. 10).

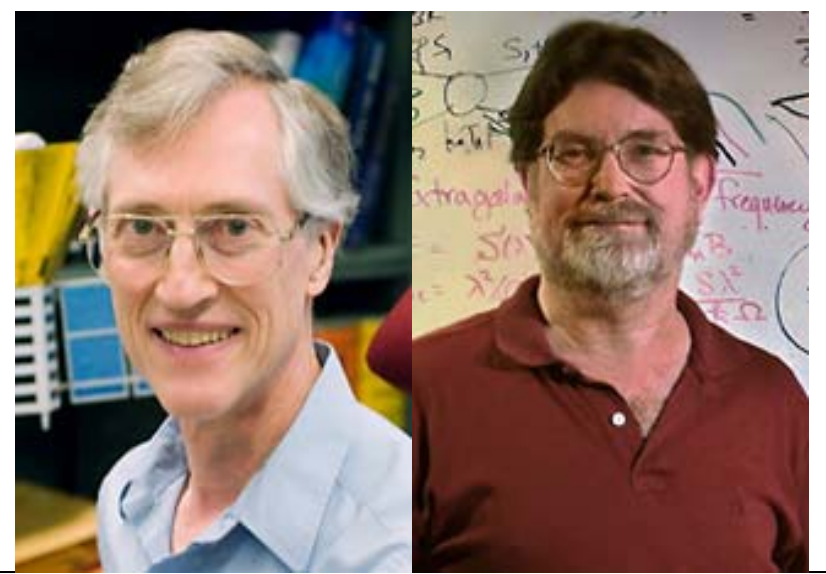

Figura 10. John C. Matter (esquerra) i George F. Smoot, científics estadounidencs guardonats amb el premi Nobel de física el 2006. (Nobelprize.org)

Aquests resultats han estat confirmats recentment amb un altre satèl-lit nord-americà, el WMAP, que ha estudiat el fons còsmic de microones amb més resolució. Mentre el COBE tenia una resolució de $7^{\circ}$-és a dir 14 vegades més ample que la lluna plena-, la del nou enginy variava, segons els instruments, de 0,9 a $0,2^{\circ}$. El resultat val la pena comparar-lo amb les dades anteriors (fig. 11 i 12). Com es pot veure, les estructures són les mateixes, però la resolució és molt millor.

La cosmologia de precisió, inaugurada amb el COBE, ja s'està desenvolupant.

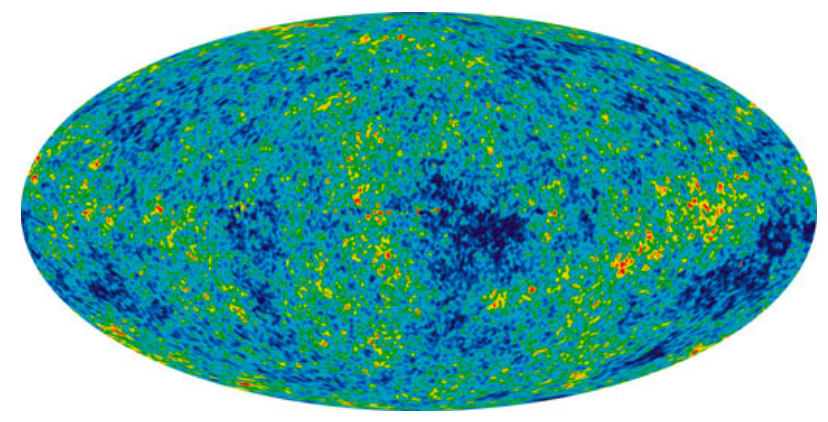

Figura 11. Dades procedents del WMAP, publicades el 2003. (NASA)

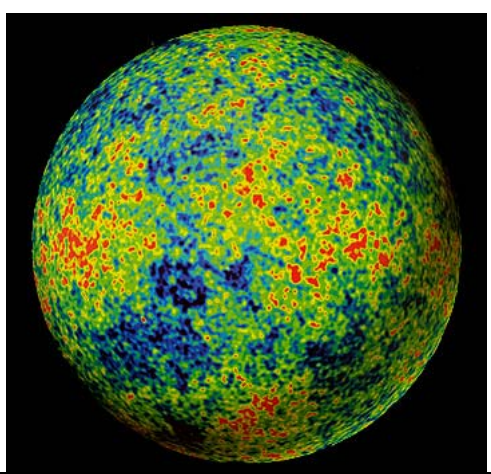

Figura 12. Imatge obtinguda a partir de dades del WMAP del fons còsmic de radiació en totes direccions.

\section{QUĖ ENS ENSENYA EL FONS COSMIC DE MICROONES?}

El fons còsmic de microones és la radiació que queda d'un moment molt concret de la història de l'Univers.

En uns primers moments es produeixen una sèrie de fenòmens que la física de partícules va aclarint.

La matèria és en estat de un plasma. Les forces entre partícules carregades són el resultat de l'intercanvi de fotons. Com que en aquestes condicions els fotons no poden seguir trajectòries rectilínies, hem d'imaginar un Univers òpticament opac (fig. 13). A més a més, la pressió de radiació tendeix a separar les càrregues entre si.

Quan més endavant es poden formar els àtoms, principalment d'hidrogen, l'absència significativa de càrregues lliures permet la difusió rectilínia dels fotons (fig. 14). En aquell moment I'Univers esdevé transparent. 


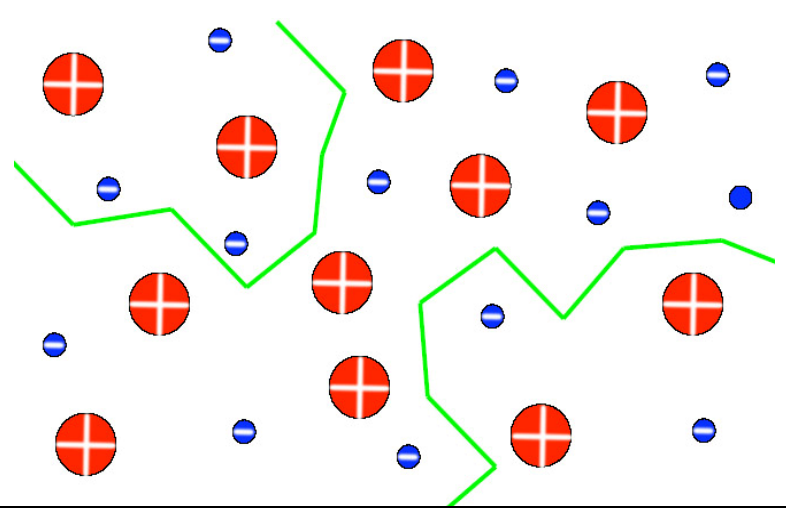

Figura 13. L'opacitat de l'Univers primitiu és deguda a les càrregues, que desvien els fotons, portadors de la interacció electromagnètica. Les línies verdes representen trajectòries de fotons.

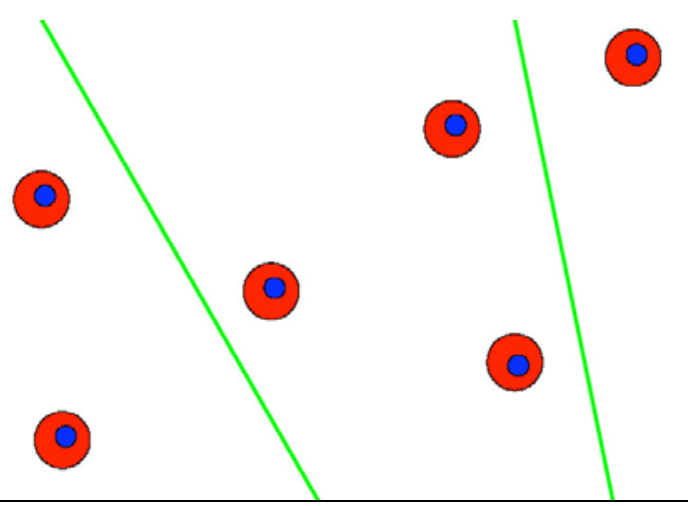

Figura 14. L'opacitat de l'Univers s'acaba quan la matèria s'organitza en àtoms neutres, indicats aquí com a càrregues elèctriques mútuament neutralitzades.
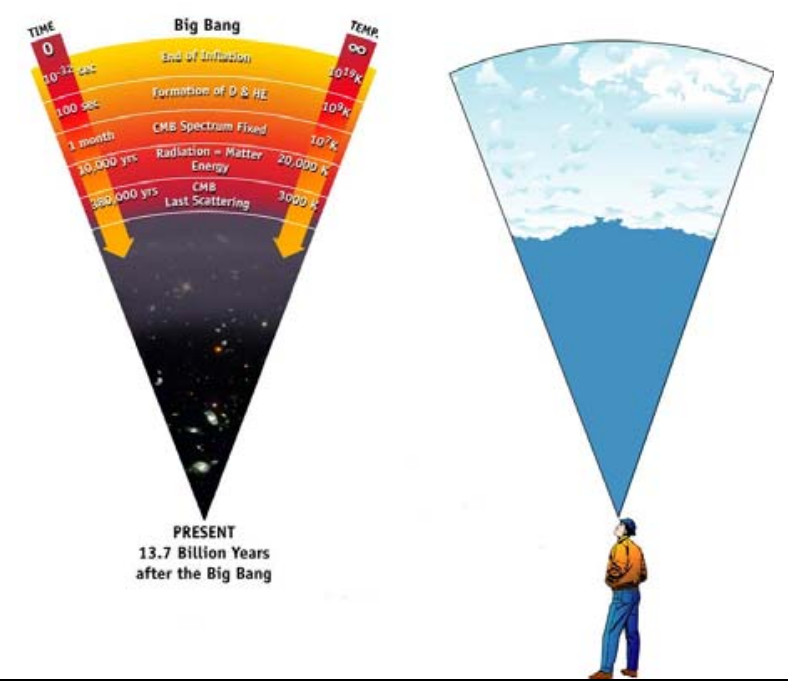

Figura 15. Comparació entre la llum que ens arriba (dreta) de la superfície del núvol, sense poder veure directament la de l'interior i (esquerra) la radiació procedent de la darrera dispersió (last scattering) just quan l'Univers esdevé òpticament transparent. (NASA)
Les petites diferències de temperatura entre punts de l'Univers en aquell moment, evidenciades per la radiació tèrmica que emetien, han arribat fins a nosaltres en forma de fons còsmic de microones. Les petites diferències de temperatura que hi perceben, doncs, corresponen a petites diferències de densitat de la matèria en el moment que l'Univers es torna transparent. Tenia prop dels 400.000 anys d'edat.

De la mateixa manera que la llum pot anar rebotant per l'interior d'un núvol però nosaltres només podem veure la que n'emergeix (fig. 15a), de l'etapa opaca de l'Univers només en podem veure el que en va sortir quan es va tornar transparent (fig. 15b), i amb una longitud d'ona que ha anat augmentant amb l'expansió de l'Univers.

Aquestes mínimes diferències de temperatura, corresponents a mínimes diferències de densitat, són les que després faran possible que els núvols de gas puguin comprimir-se per efecte gravitatori i formar les grans estructures còsmiques (fig. 16). Si la densitat hagués estat uniforme, aquestes estructures no s'haurien pogut formar. I nosaltres no hi seríem.

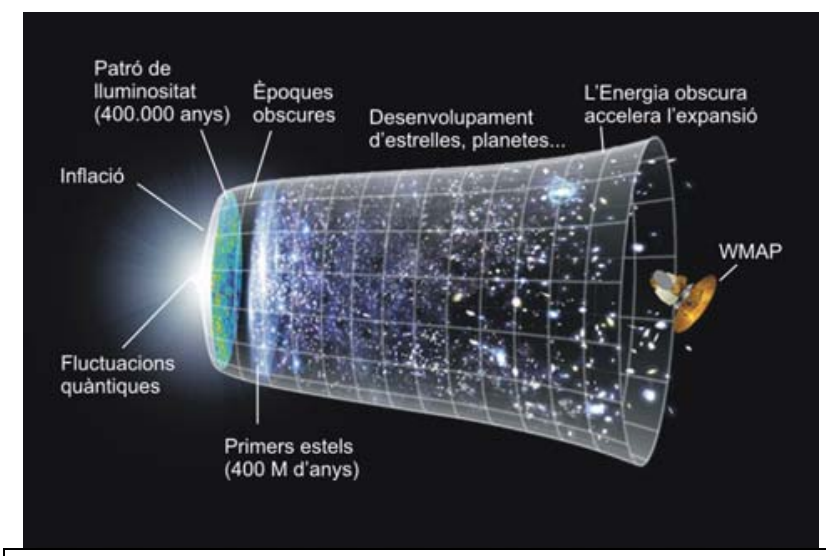

Figura 16. Representació simplificada de l'evolució de l'Univers durant la seva existència de 13.700 milions d'anys. (NASA)

De la mateixa manera que la llum que emergeix d'un núvol pot informar indirectament d'algunes característiques dels seu interior, les petites diferències de temperatura informen sobre petitíssimes fluctuacions produïdes en èpoques molt i molt primerenques. Concretament durant l'etapa coneguda com a inflació, quan es produeix una expansió ràpida, sobtada i molt breu.

\section{CAP A UNA NOVA IMATGE DE L'UNIVERS}

Les dades del fons còsmic de microones aporten proves del Big Bang: si la matèria no hagués estat interaccionant molt junta en algun moment no 
podria haver estat en l'equilibri tèrmic pràcticament ideal que les dades mostren. També donen suport a la teoria de la inflació.

I encara que no hi entrem, cal esmentar que els actuals models del Big Bang també expliquen per què l'Univers hauria de ser geomètricament "pla", tal com les mesures semblen demostrar.

Per altra banda, mesures fetes de determinades supernoves ens mostren que l'expansió de l'Univers s'accelera en comptes de frenar-se per la gravetat. Això s'explicaria per la presència d'una misteriosa energia obscura.

A més a més, la mesura dels efectes gravitatoris de la matèria fosca ha permès quantificar-la aproximadament.

Amb tot plegat, mesures i teories que van encaixant, apareix una nova imatge de l'Univers. La matèria normal, la constituïda per àtoms, no deixa de ser fortament minoritària (fig. 17).

Comparteix l'Univers amb matèria obscura (que, a diferència dels àtoms, no emet ni absorbeix llum i que només es detecta pel seus efectes gravitatoris) i amb una majoritària energia obscura (que es com- porta com una mena d'antigravetat i que ocasiona l'actual acceleració de l'expansió de l'Univers).

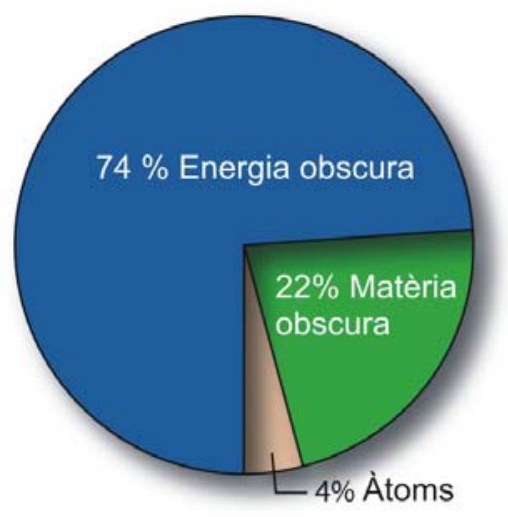

Figura 17. El contingut de l'Univers. (NASA)

Compartim, doncs, el cosmos amb dues entitats ben misterioses ja que, de moment, ben poca cosa se'n sap. El llibre de la ciència mostra pàgines en blanc, esperant que algú que les escrigui. 